Kingdom, both of which received a second lease of life earlier this month.

One of these schemes, supported by the Biotechnology and Biological Sciences Research Council (BBSRC), coordinates the UK bioinformatics community. Since 1994, the scheme has concentrated on developing software that would enable biologists without information technology (IT) skills to use some of the many tools important to their trade that are found on the World Wide Web. At a meeting earlier this month, the steering committee of the scheme decided to change the focus to training. Andy Brass, who runs a masters' degree course in bioinformatics at the University of Manchester and is a member of the committee, says, "We have a massive skills shortage. We need training at every level." The main aim will be to "train the trainers", says Brass, adding, "There are very few academics with the knowledge to teach bioinformatics because they have all been nicked by the companies." The view is echoed by others, and could account for Lyall's optimism.
The United Kingdom's second public scheme to promote bioinformatics is jointly funded by the BBSRC and by the Engineering and Physical Sciences Research Council. It too was started in 1994 (spending $\mathfrak{E} 1$ million per year and making 25 awards in three years). This scheme was also renewed for a further three years earlier this month. Chris Miles, who heads the initiative for the BBSRC, explains that research proposals must have both a strong biological and computational component. During the next phase, researchers will address priorities such as finding methods for condensing and representing data visually and seeking informatics techniques allowing the prediction of protein structure from sequence data.

In Germany (see below) the country's main grant-giving body has launched a sixyear bioinformatics programme, while in France, CNRS has allocated FFr 15 million (\$2.6 million) for bioinformatics research this next year. Not all French scientists are convinced that they will see the money. Jean Thierry-Mieg from the CNRS in Montpellier says that during the past five years spending in bioinformatics has been announced more than once, but because of political disagreements no money was forthcoming. The tide does seem to be turning, though. France is setting us a new sequencing laboratory in Paris and the University of Versailles is teaching a dedicated course on bioinformatics.

The picture elsewhere is less focused. Cecilia Saccone, a professor in the department of biochemistry and molecular biology at the University of Bari and one of Italy's leading bioinformaticists, is working with colleagues to design a bioinformatics doctoral programme for the country. Saccone has already started a project in bioinformatics, but Italy's national research council (CNR), although admitting that the subject is important, says that there is no money to support it.

Spain's leading light in bioinformatics, Alfonso Valencia from the Centro Nacional de Biotecnologia in Madrid, is coordinating a group of researchers to promote training. Uniquely for a scientist, Valencia says: "We probably have enough money for bioinfor-

\title{
Germany on the trail of the Americans
}

Germany will not quickly end

North America's lead in

bioinformatics. But in the

current biotechnology boom, the prospects seem bright.

Determined to make up for its lag in biotechnology research, a consequence of vociferous public opposition to genetic engineering, the German ministry of research (BMBF) has in the past few years launched several campaigns. Bioinformatics is a vital part of this initiative. Between 1993 and 1996, for example, the BMBF allocated DM37 million (US\$20 million) in research grants and pumped a further DM30 million into research institutes with a strong interest in bioinformatics. The BMBF plans to increase this support.

In addition, the Deutsche Forschungsgemeinschaft (DFG), Germany's main grantgiving body, is about to launch a six-year bioinformatics programme that will distribute about DM5 million in project grants in its first two years. The BMBF also has a scheme called Bioregio, a regional competition for a prize of DM150 million. Regions have to present a collaborative programme involving industry and academic research institutes.

One company to benefit from the local contacts this programme promotes is Heidelberg-based பON Bioscience. Founded in spring this year, $\amalg O N$ offers commercial services in bioinformatics and has ambitious plans to become Europe's leader. As a result of close collaboration with the European Molecular Biology Laboratory (EMBL), located on the same campus, it has been able to adapt EMBL's developments - efficient software and the fastest sequencer in the world - to its own needs.

UON is a sign of the good times that are almost certain to come for bioinformatics in Germany. The company started with 10 employees, will recruit a further 20 before the end of the year, and plans further expansion. "The technology was there, the human resources were there and we were just the first ones who had the idea to use it commercially. We filled a vacuum," says Peter Wiesner, senior manager of business development. The traditional large German pharmaceutical companies also have a growing need for specialists in bioinformatics, and find there are simply too few around. "Job opportunities in the field are so good that, at the moment, potential employers are finding the cupboard bare," says Hugo Kubinyi, head of drug design at BASF.

Academic institutes have even more ground for concern. "The battle between industry and academic research for competent bioinformaticists is, understandably, almost always won by industry," says Sandor Suhai, head of the department of molecular biophysics at the Deutsches Krebsforschungszentrum (DKFZ, the German national cancer research institute) in Heidelberg. In his group of 30 scientists (mainly graduate students) only two plan a career in academic research, says Suhai: industry can offer long-term employment, high salaries and sometimes more exciting jobs. He complains about the high turnover in his group and says that he gets too few responses to advertisements.

The first university course for scientific informatics was established in response to this need in 1989 at Bielefeld. "We teach the basics of informatics but then focus on methods relevant to biology. The biology we teach is similarly restricted to that relevant to bioinformatics," says Robert Giegerich, dean of the technical faculty. Despite sceptics who believe the graduates are neither informaticists nor biologists, he has no doubt that his students will succeed on the job market. He believes bioinformatics will become a 'proper' science just as informatics separated from mathematics.

First employers' reactions to graduates from Bielefeld are enthusiastic. "In contrast to trained bioinformaticists, we have to teach an informaticist not only biology but also the basics of bioinformatics. This can take up to one year," says Martin Vingron, head of theoretical bioinformatics at the DKFZ.

Matthias Strobl

Matthias Strobl is a science writer in Munich, Germany 